\title{
Determinação do perfil protéico da membrana externa da Leptospira interrogans sorovariedade Hardjoprajitno
}

[Protein profile of the outer membrane of Leptospira interrogans serovar Hardjoprajitno]

\author{
B.N.Lafetá ${ }^{1}$, S. Santos ${ }^{2}$, V.L.Silva ${ }^{2}$, M.A.R. Carvalho ${ }^{2}$, C.G. Diniz ${ }^{2}$, N. Silva ${ }^{1 *}$ \\ ${ }^{1}$ Escola de Veterinária - UFMG \\ Caixa Postal 567 \\ 30123-970 - Belo Horizonte, MG \\ ${ }^{2}$ Instituto de Ciências Biológicas - UFMG - Belo Horizonte, MG
}

\begin{abstract}
RESUMO
Estudou-se o perfil das proteínas da membrana externa (PME) da Leptospira interrogans sorovariedade Hardjoprajitno por meio da eletroforese bidimensional. Foram utilizadas técnicas de extração das PME com Triton x114 e precipitação com acetona. Os géis foram corados com nitrato de prata e as imagens analisadas para determinação da massa molecular das proteínas detectadas. Foram visualizadas 35 bandas protéicas, sendo que cinco delas se destacaram por estarem em maior quantidade: 22,54KDa (LipL22), 30/26KDa (LipL32), 34,41KDa (PME34), 42,75KDa (LipL41) e 58,59KDa (LipL63).
\end{abstract}

Palavras-chave: Leptospira interrogans Hardjoprajitno, proteínas de membrana, eletroforese bidimensional

\begin{abstract}
The protein profile of the outer membrane of Leptospira interrogans serovar Hardjoprajitno was determined by two-dimensional gel electrophoresis. The outer membrane was extracted with Triton $x 114$ and the proteins were precipitated with acetone. The images were analyzed for the determination of the molecular weight of the detected proteins. Thirty-five spots for the proteins that are predominant in the outer membrane of this Leptospira were observed and five proteins were found in higher quantities: 22.54KDa (LipL22), 30/26KDa (LipL32), 34.41KDa (PME34) (2), 42.75KDa (LipL41), and 58.59KDa (LipL63).
\end{abstract}

Keywords: Leptospira interrogans serovar Hardjoprajitno, membrane proteins, two-dimensional electrophoresis

\section{INTRODUÇÃO}

A leptospirose é uma zoonose de ampla distribuição mundial. Em animais, sua importância econômica está relacionada aos prejuízos nos sistemas de produção da pecuária leiteira e de carne, principalmente em bovinos, decorrentes dos problemas reprodutivos. Abortos e mortalidade embrionária, nascimento de bezerros fracos ou prematuros, assim como natimortalidade e mastites, são os quadros mais freqüentes (Araújo et al., 2005). A leptospirose é o resultado da relação bilateral existente entre leptospira e hospedeiro, sendo um processo dinâmico, envolvendo tanto fatores relacionados ao agente quanto ao hospedeiro (Levett, 2001).

Nunes-Eduards et al. (1985) realizaram o primeiro estudo com a finalidade de verificar a composição protéica da membrana externa das leptospiras. Na investigação, utilizaram amostra de Hardjoprajitno e a técnica de marcação radioativa dos antígenos com metionina $\left(\mathrm{S}^{35}\right)$. Nove bandas $(63 ; 55 ; 51,5 ; 41,5 ; 38 ; 36 ; 35,5 ; 33$ e $21,5 \mathrm{KDa}$ ) foram identificadas como componentes da membrana externa. Outros

Recebido em 26 de novembro de 2007

Aceito em 22 de setembro de 2008

* Autor para correspondência (corresponding author)

E-mail: nivaldovet@yahoo.com.br 
autores descreveram a composição protéica da membrana externa de diversas sorovariedades de leptospira (Brown et al., 1991; Haake et al., 1999; Alves et al., 2000; Haake e Matsunaga, 2002; Lee et al., 2002; Biswas et al., 2005).

Alves et al. (2000) extraíram as proteínas de membrana externa (PME) da L. interrogans sorovariedade Pomona e realizaram o seu seqüenciamento parcial. As seqüências parciais geradas pelas proteínas de 32,40 e $45 \mathrm{KDa}$ tiveram similaridade de $95,2 \%$ com as proteínas de $L$. Interans e $90,5 \%$ com as de $L$. Kirschneri, confirmando a conservação antigênica existente entre as diversas leptospiras.

Segundo Cullen et al. (2002), as PME da $L$. interrogans sorovariedade Lai, frente às variações nas condições de cultivo, sofrem alterações passíveis de serem percebidas apenas pela eletroforese bidimensional (2D). Após a análise dos pontos protéicos pela técnica de MALDI-TOF por espectrometria de massa, esses autores constataram que as proteínas LipL32, LipL36 e LipL41 (já seqüenciadas), juntamente com a LipL48 (seqüência ainda não publicada), predominam na membrana externa da $L$. interrogans sorovariedade Lai. Das 67 proteínas separadas pela eletroforese 2D, 21 apresentaram seqüências convergentes à seqüência original da proteína LipL32. Essa proteína é o antígeno protéico imunodominante e mais abundante da membrana externa da $L$. interrogans sorovariedade Lai e apresenta atividades hemolíticas (Hauk et al., 2005).

A diferenciação no perfil de expressão tem sido importante na compreensão da baixa eficácia das vacinas comerciais, posto que as condições de crescimento de uma amostra no campo, in vivo, são diferentes das condições de crescimento de uma outra amostra da mesma sorovariedade em laboratório, in vitro, o que mudaria não apenas o perfil de expressão das PME como também o perfil de anticorpos produzidos nos animais imunizados com vacinas produzidas com amostras laboratoriais de leptospira. A diferença nos perfis das proteínas e dos anticorpos poderia justificar a baixa eficácia de muitas vacinas e direcionar os trabalhos a fim de buscar o real conhecimento de perfis protéicos mais próximos possíveis daqueles encontrados no campo.
Segundo Cullen et al. (2004), as PME de espiroquetas interagem com o ambiente e com o sistema do hospedeiro, contribuindo para a patogenia da doença. Durante a infecção, as leptospiras devem ser capazes de driblar o sistema imune do hospedeiro para efetuar uma apropriada colonização; moléculas associadas à membrana devem mediar essa interação entre o hospedeiro e o microrganismo.

A lipoproteína de 22KDa, denominada Loa22, considerada como o segundo maior constituinte das membranas externas das L. interrogans sorovariedades Lai (Cullen et al., 2002) e Manilae (Koizumi e Watanabe, 2003), foi associada à virulência das amostras de leptospiras, sendo expressa, principalmente, durante os processos de infecção, relacionandose aos casos agudos da doença (Ristow et al., 2007).

O trabalho tem como objetivo verificar o perfil protéico da membrana externa (ME) da $L$. interrogans sorovariedade Hardjoprajitno por meio da técnica de eletroforese bidimensional, a fim de identificar as proteínas expressa em maior quantidade nessa sorovariedade quando ela estiver sob condições in vitro.

\section{MATERIAL E MÉTODOS}

As amostras de L. interrogans sorovariedade Hardjoprajitno (OMS) foram cedidas pelo Laboratório de Zoonoses do Departamento de Medicina Veterinária Preventiva da UFMG. Essas amostras foram cultivadas em sistema estático, a $30^{\circ} \mathrm{C}$, utilizando-se o meio líquido EMJH (Ellinghausen e McCullough, 1965; Johnson e Harris, 1967) e iniciando-se os cultivos com um inóculo correspondente a $10 \%$ do volume final do mesmo, sendo interrompidos no sétimo dia de incubação. A concentração final foi estimada pela contagem direta em câmara de Petroff-Hausser em microscópio equipado com condensador de campo escuro sendo, em média, $1 \times 10^{9}$ leptospira/ml.

A extração da membrana externa foi realizada segundo metodologia descrita por Haake et al. (1991), e as proteínas extraídas foram precipitadas segundo Cunningham et al. (1988).

A eletroforese 2D foi realizada em tiras de gel imobilizado (Amersham Biosciences), com 
gradiente de $\mathrm{pH}$ de 4 a 7 , medindo $13 \mathrm{~cm}$ de comprimento, segundo técnica descrita por Cullen et al. (2002). O gel foi corado com nitrato de prata (Arrell et al., 2001).

A determinação da massa molecular das proteínas de membrana de $L$. Hardjoprajitno foi realizada em géis bidimensionais, que foram fotografados ao final de cada experimento. As imagens foram analisadas com o auxílio do software Gel-Pro Analyzer® 3.1 para determinar a massa molecular das proteínas. Para o programa analisar os géis $2 \mathrm{D}$, foram criadas três linhas de análise sobre os principais pontos protéicos, denominadas linhas de análise 2 (L2), 3 (L3) e 4 (L4), sendo que na linha 1 (L1) está o padrão de massa molecular.

\section{RESULTADOS}

O número total de proteínas avaliado visualmente no gel correspondeu a 70 distintos pontos protéicos. $\mathrm{O}$ cálculo das massas moleculares dos 35 principais pontos protéicos foi feito com a utilização do Gel-Pro Analyzer ${ }^{\circledR}$ 3.1. (Fig.1 e Tab. 1). A análise global das PME da $L$. Hardjoprajitno por meio da eletroforese 2D mostrou que três proteínas apresentaram-se com as maiores concentrações: $22,54 \mathrm{KDa}$ (r10), $34,41 \mathrm{KDa}(\mathrm{r} 5)$ e $42,75 \mathrm{KDa}(\mathrm{r} 3)$. A proteína que aparece em maior quantidade no gel encontra-se na linha de análise L3 e possui massa molecular igual a $22,54 \mathrm{KDa}$ (r10). A segunda proteína em ordem de concentração, r5, aparece tanto nas linhas de análise L2 e L3, como entre elas, apresentando massas moleculares iguais a $34,41 \mathrm{KDa}$ e $33,84 \mathrm{KDa}$, respectivamente. Pequenas diferenças de massas moleculares não são consideradas pelo programa, recebendo as duas proteínas o mesmo código e denominadas PME34 (LipL34).

A proteína com massa molecular mais próxima a $32 \mathrm{KDa}$ se encontra nas linhas L2 e L3, tendo massas moleculares estimadas em 30,08KDa (r6) e $31,81 \mathrm{KDa}(\mathrm{r} 6)$, respectivamente. Na região da linha de análise L2 e L3, existem pequenas bandas protéicas, denominadas de r7 e r8, cujas massas moleculares estão estimadas em
27,81KDa e 26,44KDa. Essas proteínas deixaram um arraste forte na parte alcalina do gel durante a focalização isoelétrica, sugerindo serem formas desnaturadas da LipL32.

Uma PME de 42,75KDa foi encontrada nas linhas de análise 2 e 3 (r3), cuja massa molecular aproxima-se à LipL41, descrita por Shang et al. (1996) e Cullen et al. (2002). Nas linhas de análise L2 e L3, apareceram duas bandas de massas moleculares calculadas em 58,59KDa e em 57,06KDa (r1), respectivamente.

\section{DISCUSSÃO}

Neste trabalho, descreve-se o perfil protéico da membrana externa da $L$. Hardjoprajitno por meio da eletroforese 2D. As proteínas com massas moleculares iguais a $22,54 \mathrm{KDa}, 34,41 \mathrm{KDa}$ e $42,75 \mathrm{KDa}$ apresentaram-se fortemente coradas e em quantidades maiores que as demais proteínas visualizadas no gel 2D, sugerindo serem estas as principais proteínas constituintes da membrana externa da L. interrogans sorovariedade Hardjoprajitno. Destaca-se a proteína de 22,54KDa, aqui denominada de LipL22, como o principal componente das PME, descrita como uma lipoproteína conservada em outras sorovariedades de leptospiras patogênicas, incluindo a detecção de anticorpos em soros de camundongos convalescentes de leptospirose, o que mostra a correlação entre a sua presença e a patogenicidade das amostras (Cullen et al., 2002; Koizumi e Watanabe, 2003; Ristow et al., 2007). Neste trabalho, não foi realizada, por não ser o objetivo proposto, a avaliação entre as respostas imunes de animais infectados e convalescentes de leptospirose causadas por L. Hardjoprajitno e a presença da LipL 22 , entretanto pode ser significativa a sua participação nas respostas imunes. O fato de se apresentar em grande quantidade, mesmo sob condições ambientais, às quais as amostras estão submetidas, vem salientar que fatores relacionados à patogenia da amostra dependentes da expressão dessa proteína não são prejudicados com a sua manutenção desta em laboratório (Cullen et al., 2002; 2004). 


\section{Lafetá et al.}

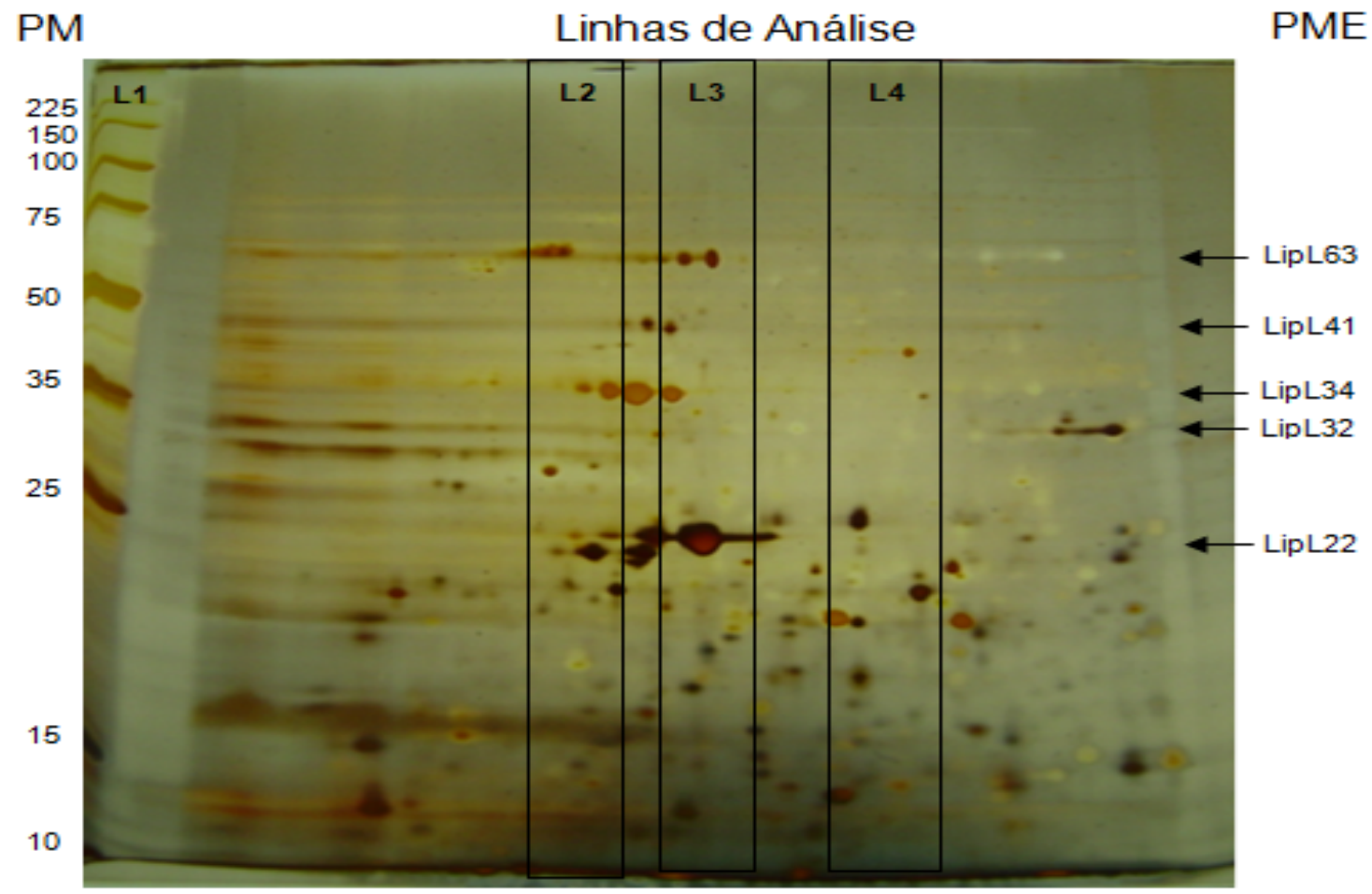

Figura 1. Gel bidimensional das proteínas de membrana externa da Leptospira interrogans sorovariedade Hardjoprajitno. PM: valores referentes às bandas do padrão de massa molecular em KDa; L1: padrão de massa molecular, L2, L3 e L4: linhas de análise; PME: marcação das principais proteínas da membrana externa.

Tabela 1. Códigos relacionados às proteínas analisadas no gel bidimensional e suas massas moleculares correspondentes

\begin{tabular}{cccc}
\hline Código & Linha de análise 2 & Linha de análise 3 & \\
\hline r1 & 58,59 & 57,06 & \\
r2 & & 44,67 & \\
r3 & 43,03 & 42,75 & \\
r4 & & 37,26 & \\
r5 & 34,41 & 33,84 & \\
r6 & 30,08 & 31,81 & \\
r7 & 27,81 & & 23,44 \\
r8 & 26,44 & & 22,62 \\
r9 & & 23,86 & 21,98 \\
r10 & 22,70 & 22,54 & \\
r11 & & \\
r12 & 21,82 & & 19,19 \\
r13 & 20,46 & & 18,98 \\
r14 & 19,74 & 19,46 & \\
r15 & 19,46 & & 16,87 \\
r16 & & 17,99 & 15,99 \\
r17 & 16,578 & 15,43 \\
r18 & & & 14,78 \\
r19 & 16,69 & & \\
r20 & 15,82 & & \\
r21 & 15,16 & &
\end{tabular}


A segunda proteína em ordem de concentração apresentou pequena variação em seu peso molecular (entre 34,41KDa e 33,84KDa). Como o programa informático não leva em consideração as pequenas diferenças de pesos moleculares, ela foi denominada Omp34. Não existem registros da existência de uma Omp34 $(34 \mathrm{KDa})$ entre as sorovariedades de $L$. interrogans, apenas a descrição de um lipopolissacarídeo de $33 \mathrm{KDa}$, de origem flagelar e com atividade antigênica, em amostras atenuadas de L. interrogans sorovariedade Grippotyphosa. (Haake et al., 1991; Cullen et al., 2002). Esta Omp34 pode ser o mesmo polipeptídeo descrito por aqueles autores, posto que, durante o processo de extração pelo Triton X114, podem ocorrer diferenças mínimas entre os pesos moleculares das proteínas (Cullen et al., 2002; 2004), como verificado neste trabalho. Deve-se acrescentar que a amostra de $L$. interrogans sorovariedade Hardjoprajitno, usada neste experimento, é também uma amostra atenuada, mantida em laboratório por muito tempo e que não passou por recentes passagens in vivo.

Nos resultados aqui expressos, dos 35 principais pontos protéicos cujas massas moleculares foram calculadas, $25(71,42 \%)$ possuem massas moleculares abaixo de $29 \mathrm{KDa}$, e, alguns deles apresentaram massas moleculares próximas às encontradas por Cullen et al. (2002) para as isoformas da LipL32. As bandas de proteínas da membrana externa de $L$. Hardjoprajitno, de $30,08 \mathrm{KDa}$ e $31,81 \mathrm{KDa}$ (r6), detectadas pelo programa Gel-Pro Analyzer® 3.1, a partir dos géis bidimensionais, sugerem que elas podem ser formas isoméricas da LipL32.

Em relação às condições de crescimento, é conhecido que as leptospiras não expressam certas PME em determinadas temperaturas e níveis baixos de disponibilidade de íons férrico, o que pode justificar essa baixa expressão da proteína de massa molecular igual a $32 \mathrm{KDa}$. Contrastando com estes resultados, ela foi detectada em grande quantidade por Cullen et al. (2002) para a sorovariedade Lai. Por ser uma lipoproteína associada à produção de hemólise, ela pode ser encontrada em maiores quantidades em sorovariedades de leptospiras responsáveis pelos quadros hemolíticos (Hauk et al., 2005). Como a $L$. Hardjoprajitno está associada a problemas reprodutivos, principalmente em bovinos, e causa menos quadros hemolíticos, a sua expressão, nesta sorovariedade de Leptospira, deve ser conseqüentemente menor. Outro aspecto a ser destacado é que a expressão da LipL32 pode ser regulada negativamente em função da baixa concentração de íons presentes no meio de cultivo EMJH.

A LipL41, considerada como uma lipoproteína altamente conservada e imunomodulante para espécies de L. interrogans (Haake et al., 1999), não foi detectada na $L$. Hardjoprajitno, pela eletroforese bidimensional. Em seu lugar, foi encontrada uma PME de 42,75KDa (r3), cuja massa molecular aproxima-se da LipL41, descrita por Shang et al. (1996) e Cullen et al. (2002). Da mesma maneira, pode-se considerar que as duas bandas de $58,59 \mathrm{KDa}$ e $57,06 \mathrm{KDa}$ visualizadas neste experimento são componentes da LipL63, descrita por Haake e Matsunaga (2002) e Lee et al. (2002), posto que, durante o processo de extração e solubilização com Triton $\mathrm{X} 114$, ocorrem alterações estruturais nas PME das espiroquetas e, conseqüentemente, diminuição das massas moleculares (Cullen et al., 2004). Essa LipL63 é uma proteína de transmembrana de espiroquetas cuja função relaciona-se com quadros hemolíticos da leptospirose (Lee et al., 2002), sendo constantemente detectada em soros de animais imunizados (Nunes-Edwards et al., 1985).

O perfil protéico total das membranas externas das principais sorovariedades de leptospiras está ainda em fase de determinação e é dependente do processo de extração, encontrando-se muitas formas isoméricas de uma mesma proteína. $\mathrm{O}$ uso da técnica de eletroforese 2D possibilita estudar melhor os perfis das PME desses microrganismos e pode contribuir para elucidar as suas relações com as respostas imunes dos indivíduos afetados pela leptospirose.

\section{AGRADECIMENTOS}

Este trabalho foi realizado com o apoio financeiro do Laboratório VALLÉE S/A e da Fundação de Estudo e Pesquisa em Medicina Veterinária e Zootecnia, FEPMVZ- Coordenação Preventiva. Os autores agradecem a colaboração técnica de Antônio Benjamin de Paula para sua execução. 


\section{REFERÊNCIAS BIBLIOGRÁFICAS}

ALVES, S.F.; LEFEBVRE, R.B.; PROBER, W., Amino acid sequences of proteins from Leptospira serovar Pomona. Mem. Inst. Oswaldo Cruz, v.95, p.503-504, 2000.

ARAÚJO, V.E.M.; MOREIRA, E.C.; NAVEDA, L.A.B. et al. Freqüência de aglutininas antiLeptospira interrogans em soros sangüíneos de bovinos, em Minas Gerais, de 1980 a 2002. Arq. Bras. Med. Vet. Zootec., v.57, p.430-435, 2005.

ARRELL, D.K.; NEVEROVA, I.; FRASER, H. et al. Proteomic analysis of pharmacologically preconditioned cardiomyocytes reveals novel phosphorylation of myosin light chain 1. Circ. Res., v.89, p.480-487, 2001.

BISWAS, D.; ROY, S.; VIJAYACHARI, P. et al., Comparison of immunoreactive proteins of commonly circulating serogroups of Leptospira in Andaman Islands, India. Indian J. Med. Res., v.121, p.151-158, 2005.

BROWN, J.A.; LeFEBVRE, R.B.; PAN, M.J. Protein and antigen profiles of prevalent serovars of Leptospira interrogans. Infect. Immun., v.59, p.1772-1777, 1991.

CULLEN, P.A.; CORDWELL, S.J.; BULACH, D.M. et al. Global analysis of outer proteins from Leptospira interrogans serovar Lai. Infect. Immun., v.70, p.2311-2318, 2002.

CULLEN, P.A.; HAAKE, D.A.; ADLER, B. Outer membrane proteins of pathogenic spirochetes. FEMS Microbiol. Let., v.28, p.291318, 2004.

CUNNINGHAM, T.M.; WALKER, E.M.; MILLER, J.N. et al. Selective release of Treponema pallidum outer membrane and associated polypeptides with triton $\mathrm{x}-114 . J$. Bacteriol., v.170, p.5789-5796, 1988.

ELLINGHAUSEN Jr., H.C.; McCULLOUG, W.G. Nutrition of Leptospira Pomona and growth of 13 serotypes: fractionation of oleic albumin complex and a medium of bovine albumin and polysorbate 80. Am. J. Vet. Res., v.26, p.45-51, 1965.

HAAKE, D.A.; WALKER, E.M.; BLANCO, D.R. et al. Changes in the surface of Leptospira interrogans serovar Grippotyphosa during "in vitro" cultivation. Infect. Immun., v.59, p.11311140, 1991.
HAAKE, D.A.; MAZEL, M.K.; MCCOY, A.M. et al. Leptospiral outer membrane proteins OmpL1 and lipL41 exhibit synergistic immunoprotection. Infect. Immun., v.67, p.65726582, 1999.

HAAKE, A.D.; MATSUNAGA, J. Characterization of the leptospiral outer membrane and description of three novel leptospiral membrane proteins. Infect. Immun., v.70, p.6572-6582, 2002.

HAUK, P.; NEGRITTO, S.; ROMERO, E.C. et al. Expression and characterization of HlyX hemolysin from Leptospira interrogans serovar Copenhageni: Potentiation of activity by LipL32. Bioch. Biophys. Res. Comm., v.333, p.13411347, 2005.

JOHNSON, R.C.; HARRIS, V.G. Differentiation pathogenic and saprophytic Leptospira. $J$. Bacteriol., v.94, p.27-31, 1967.

KOIZUMI, N.; WATANABE, H. Molecular cloning and characterization of a novel leptospiral lipoprotein with OmpA domain. FEMS Microbiol. Letters, v.226, p.215-219, 2003.

LEE, S.H.; KIM, K.A.; PARK, Y.G. et al. Identification and partial characterization of a novel hemolysin from Leptospira interrogans serovar Lai. Gene, v.254, p.19-28, 2002.

LEVETT, P. Leptospirosis. Clin. Microbiol. Rev., v.14, p.269-326, 2001.

NUNES-EDWARDS, P.L.; THIERMANN A. B.; BASSFORD, P. J. et al. Identification and characterization of Leptospira interrogans serovar Hardjo. Infect. Immun., v.48, p.492-497, 1985.

RISTOW, P.; BOURHY, P.; McBRIDE, F.W.C. et al. The OmpA-like protein Loa22 is essential for leptospiral virulence. PLOS Pathogens, n. 7, p.894-903, 2007.

SHANG, E.S.; SUMMERS, T.A.; HAAKE, D.A. Molecular cloning and sequence analysis of the gene encoding LipL41, a surface-exposed lipoprotein of pathogenic Leptospira species. Infect. Immun., v.64, p.2322-2330, 1996. 